\title{
Health-related quality of life in obstructive sleep apnoea
}

\author{
Y. Lacasse, C. Godbout, F. Sériès
} Health-related quality of life in obstructive sleep apnoea. Y. Lacasse, C. Godbout,
F. Sériès. (C) ERS Journals Ltd 2002 .

ABSTRACT: The identification of the areas of quality of life (QoL) most likely to be affected by obstructive sleep apnoea (OSA) would be an important step in the evaluation of the impact of the disease and its treatment modalities. The objective of this study was to describe the impact of OSA on patients' QoL.

A list of 186 items potentially related to QoL of patients with OSA was constructed. From this list, consecutive patients were asked, at the time of the diagnosis, to identify the most significant items and to grade their importance on a 5-point scale. The item impact was determined from the proportion of patients who identified it as important, and the mean importance score attributed to this item (impact score=frequency $x$ importance).

One hundred patients (82 male; mean age: 51 yrs) were interviewed. The items having the most important impact on QoL clustered into five domains: 1) daytime symptoms; 2) nocturnal symptoms; 3) limitation of activities; 4) emotions; and 5) interpersonal relationships.

The impact of obstructive sleep apnoea on quality of life is not limited to excessive daytime sleepiness. Obstructive sleep apnoea significantly contributes to the impairment of all domains of what is usually referred to as "health-related quality of life".

Eur Respir J 2002; 19: 499-503.
The potential impact of sleep apnoea on the health of individuals who suffer from the disease is undeniable. Retrospective studies have indicated an association between sleep apnoea and cardiovascular- and cerebrovascular-related morbidity and mortality [1-3]. Sleep apnoea has also been linked to an increased risk of road accidents [4]. In small studies, excessive daytime sleepiness, fatigue, irritability and changes in personality have also been attributed to nocturnal oxyhaemoglobin desaturation $[5,6]$ and to the chronic sleep deprivation caused by its fragmentation [7].

Treatment decisions are usually based on the effect of the sleep disorders on daytime symptoms and cardiopulmonary function, as well as on the absolute number of episodes of apnoea or hypopnoea [8]. Nevertheless, treatment efficacy is most often measured in terms of physiological response on control sleep recordings. Early studies in which obstructive sleep apnoea (OSA)-related symptoms were measured, have been limited to the description of neurocognitive impairment related to the disease [9-12]. Thus, the identification of the areas of patients' healthrelated quality of life (QoL) most likely to be specifically affected by OSA, would be important as an initial step in the full evaluation of the impact of the disease and its treatment modalities. Accordingly, the objective of this study was to describe the impact of OSA on the QoL of patients suffering from the disease.
Centre de recherche, Centre de pneumotaire de cardiologie et de pneumologie de 1'Université Laval, Québec, Canada.

Correspondence: Y. Lacasse, Centre de Pneumologie, Hôpital Laval, 2725 Chemin Ste-Foy, Ste-Foy, P. Quebec G1V 4G5, Canada.

Fax: 4186564762

E-mail: Yves.Lacasse@med.ulaval.ca

Keywords: Obstructive sleep apnoea quality of life

Received: February 192001

Accepted after revision October 92001

This study was supported by the Quebec Lung Association. logie, Hôpital Laval, Institut universi-

\section{Patients}

The study was conducted in French in the sleep laboratory of Laval Hospital (Quebec City). Adult patients with recently diagnosed OSA were eligible for the study. Diagnostic criteria for OSA included: 1) an apnoea plus hypopnoea index $\geqslant 15$ (an apnoeic event being defined as a cessation of the oronasal flow for at least $10 \mathrm{~s}$, and hypopnoea, as a $50 \%$ decrease in the nasal pressure signal associated with a desaturation $>3 \%$ [13]), and/or arousal; or 2) typical nocturnal home oximetry recording showing repetitive, shortduration fluctuations in arterial haemoglobin saturation in patients with excessive daytime sleepiness [14].

\section{Item generation}

First, a comprehensive list of impairments (items) that might be important to patients with OSA was generated. These items were drawn from a number of sources: 1) a review of the literature dealing with QoL in patients with sleep apnoea; 2) consultations with clinicians with extensive experience evaluating and treating OSA patients; 3 ) currently available sleepiness questionnaires [15-17]; and 4) semi-structured interviews with patients with OSA. Individual interviews were conducted until five consecutive patients could 
not elicit any additional item. Fifteen patients took part in the semi-structured interviews. A list of 186 items was thus generated.

\section{Item reduction and statistical analysis}

From this list, 100 consecutive newly diagnosed and untreated patients were asked to identify the items they thought were the most significant for them, and to grade their importance on a 5-point Likert scale (1: this bothers me a little; 2 : this bothers me somewhat; 3 : this bothers me quite a bit; 4 : this bothers me a lot; and 5: this bothers me very, very much) [18].

The number of items were reduced and organized into domains using the "clinical impact method" [19]. In this method, the impact of each item is determined from the proportion of patients who identified it as important, and the mean importance score attributed to the item (impact score=frequency $\times$ importance). The items were ranked according to their impact score. Those items associated with an impact score $\geqslant 1.5$ (which corresponds to a mean frequency of $50 \%$ and a mean importance of 3 on the 5-point Likert scale) were retained for further analysis. The related items were then grouped into domains on the basis of the authors' clinical judgement. Within each domain, a correlation matrix was generated to identify the pairs of highly correlated items (Pearson's coefficient of correlation $\geqslant 0.50$ ). From each of these pairs, the number of items were further reduced by eliminating the item with the lowest impact score, providing that the items were felt to measure the same construct.

The "clinical impact method" was preferred over the "factor analysis method", in which mathematical linkage between items is explored. Although both methods may lead to the selection of different items, significant overlap usually exists when they are compared. Neither of the methods has proved superior to the other in selecting items to describe QoL in specific health conditions [19]. The "clinical impact method" was selected for clarity and simplicity, and to preserve face and content validity.

\section{Impact scores according to the method of diagnosis}

Since the patients diagnosed with OSA by home oximetry may have more severe disease (at least in terms of oxygen desaturation) than those identified by polysomnography, the impact scores obtained for each item according to the method of diagnosis were also compared. This was done by comparing the impact score distribution and rank order in both groups using an unpaired t-test and a Spearman's rank correlation analysis.

\section{Results}

\section{Patients}

Fifteen patients contributed to the item generation process. Then, 104 consecutive patients were invited to participate in the item reduction process. Four of
Table 1.-Clinical and sociodemographical characteristics of the study patients

\begin{tabular}{lcc}
\hline Characteristics & \multicolumn{2}{c}{ Phases of the study } \\
\cline { 2 - 3 } & $\begin{array}{c}\text { Item } \\
\text { generation }\end{array}$ & $\begin{array}{c}\text { Item } \\
\text { reduction }\end{array}$ \\
\hline Patients n & 15 & 100 \\
Sex M:F & $13: 2$ & $86: 14$ \\
Age yrs & $54 \pm 8$ & $51 \pm 10$ \\
Method of diagnosis & & \\
$\quad$ Polysomnography n & 8 & 69 \\
$\quad$ Nocturnal oximetry n & 7 & 31 \\
Body mass index & $34 \pm 6$ & $36 \pm 9$ \\
Neck circumference cm & $42 \pm 4$ & $43 \pm 4$ \\
Apnoea/hypopnoea index & $26 \pm 9$ & $41 \pm 24$ \\
Duration of symptoms & $8(2-25)$ & $10(0.5-40)$ \\
$\quad$ median (range) & & \\
Living with a spouse $\mathrm{n}$ & 13 & 93 \\
Currently working & 11 & 72 \\
Education yrs & $14 \pm 3$ & $14 \pm 4$ \\
\hline
\end{tabular}

Data are presented as mean \pm SD unless otherwise stated.

M: male; F: female. ${ }^{\#}$ : p=0.09 (two-sided unpaired t-test).

them were excluded from the analysis: one declined participation and three were not available for interview. The demographical and clinical characteristics of the patients who contributed to the item generation and item reduction are summarized in table 1. No significant differences in sociodemographical or clinical characteristics were found between the patients who were interviewed, either in the item generation or the item reduction phases of the study.

\section{Item reduction}

From the initial pool of 186 items, 83 had a mean impact score $\geqslant 1.5$. Using clinical judgement, these 83 items were grouped into five domains: 1) daytime symptoms; 2) nocturnal symptoms; 3) limitation of activities; 4) emotions; and 5) interpersonal relationships. Within each domain, by eliminating items measuring the same impairment, the number of items was brought down to 33. These domains and items thus represent the areas of patients' QoL that are most affected by OSA (table 2).

\section{Impact scores according to the method of diagnosis}

No major differences were found in the impact scores obtained from patients diagnosed with OSA using home oximetry and those in whom the diagnosis was made with polysomnography (home oximetry; mean \pm SD impact score: $1.55 \pm 0.96$, interquartile range: $0.77-2.10$ versus polysomnography; $1.40 \pm 0.78$, $0.86-1.87 ; \mathrm{p}=0.09)$. A very high agreement on the rank of impact scores in both groups was also found (Spearman's coefficient of correlation: 0.88; $\mathrm{p}<0.0001)$. This finding indicated that the impact scores attached to each item were similar in both groups and supported the hypothesis that the impairment of QoL is only loosely correlated with OSA severity. 
Table 2. - Item reduction: highest scoring of the original 186 items in 100 consecutive and untreated patients

\begin{tabular}{|c|c|c|c|}
\hline Domains and items & Frequency $^{\#}$ & Importance & Impact score \\
\hline \multicolumn{4}{|l|}{ Diurnal symptoms } \\
\hline Unrefreshing sleep & 90 & 3.8 & 3.42 \\
\hline Excessive fatigue & 77 & 4.2 & 3.26 \\
\hline Difficulty staying awake & 81 & 4.0 & 3.20 \\
\hline Falling suddenly asleep & 56 & 3.4 & 1.91 \\
\hline Congested nose upon awakening & 62 & 3.1 & 1.91 \\
\hline Difficulty with memory & 63 & 3.0 & 1.88 \\
\hline Aching all over upon awakening & 52 & 3.5 & 1.80 \\
\hline Attention deficit & 57 & 3.1 & 1.79 \\
\hline Lack of concentration & 55 & 3.2 & 1.77 \\
\hline \multicolumn{4}{|l|}{ Nocturnal symptoms } \\
\hline Snoring & 96 & 3.4 & 3.23 \\
\hline Waking up often during the night & 83 & 3.4 & 2.80 \\
\hline Waking up often to void & 87 & 3.0 & 2.59 \\
\hline Waking up feeling like you were choking & 65 & 3.7 & 2.41 \\
\hline Dry mouth upon awakening & 72 & 3.0 & 2.16 \\
\hline Waking up early in the morning & 70 & 2.8 & 1.95 \\
\hline Restless sleep & 61 & 2.7 & 1.65 \\
\hline \multicolumn{4}{|l|}{ Activities } \\
\hline Falling asleep if not active & 87 & 3.5 & 3.02 \\
\hline Fighting the urge to fall asleep & 85 & 3.6 & 3.02 \\
\hline Need of naps during the day & 75 & 3.1 & 2.30 \\
\hline Difficulty staying awake while reading & 67 & 3.4 & 2.27 \\
\hline Difficulty staying awake while driving & 47 & 4.2 & 1.98 \\
\hline Feeling that activities require an extra effort to complete & 50 & 3.9 & 1.95 \\
\hline Diminished performance at work & 44 & 4.2 & 1.85 \\
\hline \multicolumn{4}{|l|}{ Emotions } \\
\hline Feeling impatient & 69 & 4.0 & 2.73 \\
\hline Concerns about weight & 74 & 3.7 & 2.73 \\
\hline Always feeling unable to regain strength & 64 & 4.0 & 2.58 \\
\hline Feeling anxious & 59 & 4.1 & 2.41 \\
\hline Feeling depressed & 53 & 3.9 & 2.07 \\
\hline Concerns about health & 45 & 3.8 & 1.70 \\
\hline \multicolumn{4}{|l|}{ Social interactions } \\
\hline Bothering the sleep of the partner & 74 & 4.1 & 3.04 \\
\hline Reluctance to stay overnight with friends due to snoring & 53 & 4.1 & 2.18 \\
\hline Lack of interest in going out & 51 & 3.6 & 1.82 \\
\hline Concerns about bothering others & 42 & 4.2 & 1.76 \\
\hline
\end{tabular}

${ }^{\#}$ : proportion of patients who identified this item as important; " mean importance (on a 5-point Likert scale) of this item among the patients who identified it as relevant.

\section{Discussion}

The impact of OSA on QoL is not limited to excessive daytime sleepiness and an increased risk of cerebrovascular and cardiovascular events. From the results of this study, it is concluded that OSA clearly affects important domains of QoL which remain unexplored in the sleep laboratory. The concept of health-related QoL usually refers to the patients' perception of performance in at least one of four important domains: 1) somatic sensation; 2) physical function; 3) emotional state; and 4) social interaction [20]. The domains of QoL elicited by the patients who participated in this study corresponded to the same dimensions.

In addition, this study was helpful in clarifying the clinical features of OSA. Symptoms commonly attributed to OSA [21] did not emerge as predominant symptoms reported by the patients in this study. Interesting examples included morning headaches (frequency: $48 \%$; mean importance:
2.7; impact score: 1.28) and nocturnal oesophageal reflux (which was not elicited from any of the patients).

Given the lack of correlation between the impairment of QoL and the severity of sleep apnoea [22], it is the authors' view that QoL should be measured directly. The measurement of physiological parameters cannot be used as a surrogate outcome for health-related QoL in sleep apnoea. Recently, a number of investigations have included the measurement of QoL in the assessment of the effect of treatment modalities in OSA [23-25]. Most have used generic instruments (such as the Medical Outcome Survey, Short Form (SF)-36 [26]) to do so. Although generic questionnaires are designed to measure all important aspects of QoL, they are less likely to detect change in QoL than a disease-specific questionnaire which focuses on specific areas of QoL [27]. Such a disease-specific questionnaire is clearly in need in OSA research [28].

The development of an OSA-specific questionnaire 
should therefore be preceded by identification of the areas of QoL most affected by the disease. This study should be seen as an preliminary step in the development of such a questionnaire. The development of the Sleep Apnoea QoL Index [29] was initiated with a study using the same methodology as that adopted in this study. Those investigators used only the "impact method" to reduce their items and to group them into domains. Both studies resulted in the identification of items that were remarkably similar. This finding supports the content validity (i.e. the instrument's comprehensiveness) of the Sleep Apnoea QoL Index. However, this study differs from their work in that only patients who had not yet received any treatment were included. It was felt that the inclusion of consecutive patients, at the time the diagnosis of OSA was made and before the initiation of any therapy, would better reflect the true impact of the disease on patients' QoL.

To illustrate this point, the two items that ranked highest in each domain in this study were selected (table 2). The impact score of each item was then compared to that found by FLEMONS and REIMER [29] for the corresponding item. Although many items were elicited in both studies, there were often large differences in their impact scores. This finding was interpreted as a possible consequence of the difference in the study populations in the two studies. Whereas $80 \%$ of the patients included in FLEMONS and REIMER's [29] study had attempted some type of therapy, only patients who were untreated were included in this study. It could be hypothesized that the inclusion of treated patients in a study aimed at the identification of the domains of QoL most affected by the disease, may underestimate the true impact of the disease. Consequently, this situation may bear on the relevance of items selected for inclusion in the final questionnaire and its measurement properties which remain to be determined.

In conclusion, the impact of obstructive sleep apnoea on quality of life is not limited to excessive daytime sleepiness. It is clear from this study that quality of life assessment in obstructive sleep apnoea must tap into major areas that include daytime symptoms, nocturnal symptoms, limitation of activities, emotional function and interpersonal relationships. Hence, obstructive sleep apnoea significantly contributes to the impairment of all domains of what is usually referred to as "health-related quality of life". The limited correlation between the impairment of quality of life and the severity of sleep apnoea reinforces the need for direct measurement of health status in obstructive sleep apnoea. The items identified in this descriptive study will be used to construct a new obstructive sleep apnoea-specific quality of life questionnaire. In the absence of a "gold standard" defining quality of life in obstructive sleep apnoea, the validation of such a questionnaire must rely on an approach called "construct validation". This process involves comparisons between measures (such as questionnaire scores and laboratory data) and examines the logical relations that should exist between them [27].

\section{References}

1. Wilcox I, Grunstein RR, Hedner JA, et al. Effect of nasal continuous positive airway pressure during sleep on 24-hour blood pressure in obstructive sleep apnea. Sleep 1993; 16: 539-544.

2. Hung J, Whitford EG, Parsons RW, Hillman DR. Association of sleep apnoea with myocardial infarction in men. Lancet 1990; 336: 261-264.

3. Palomaki H. Snoring and the risk of brain infarction. Stroke 1991; 22: 1021-1025.

4. Young T, Blustein J, Finn L, Palta M. Sleepdisordered breathing and motor vehicle accidents in a population-based sample of employed adults. Sleep 1997; 20: 608-613.

5. Kribbs NB, Pack AI, Kline LR, et al. Effects of one night without nasal CPAP treatment on sleep and sleepiness in patients with obstructive sleep apnea. Am Rev Respir Dis 1993; 147: 1162-1168.

6. Naegele B, Thouvard V, Pepin JL. Deficits of cognitive executive functions in patients with sleep apnea syndrome. Sleep 1995; 18: 43-52.

7. Colt HG, Haas H, Rich GB. Hypoxemia versus sleep fragmentation as a cause of excessive daytime sleepiness in obstructive sleep apnea. Chest 1991; 100: $1542-$ 1548.

8. Loube DI, Gay PC, Strohl KP, Pack AI, White DP, Collop NA. Indications for positive airway pressure treatment of adult obstructive sleep apnea patients: a consensus statement. Chest 1999; 115: 863-866.

9. Findley LJ, Barth JT, Powers DC, Wilhoit SC, Boyd DG, Suratt PM. Cognitive impairment in patients with obstructive sleep apnea and associated hypoxemia. Chest 1986; 90: 686-690.

10. Berry DTR. Nocturnal hypoxia and neuropsychological variables. J Clin Exp Neuropsychol 1986; 8: 229238.

11. Greenberg GD, Watson RK, Deptula D. Neuropsychological dysfunction in sleep apnea. Sleep 1987; 10: 254-262.

12. Derderian SS, Bridenbaugh RH, Rajagopal KR. Neuropsychologic symptoms in obstructive sleep apnea improve after treatment with nasal continuous positive airway pressure. Chest 1988; 94: 1023-1027.

13. Block AJ, Boysen PG, Wynne JW, Hunt LA. Sleep apnea, hypopnea and oxygen desaturation in normal subjects. A strong male predominance. $N$ Engl J Med 1979; 300: 513-517.

14. Sériès F, Marc I, Cormier Y, La Forge J. Utility of nocturnal home oximetry for case finding in patients with suspected sleep apnea hypopnea syndrome. Ann Intern Med 1993; 119: 449-453.

15. Hoddes E, Zarcone V, Smythe H, Phillips R, Dement WC. Quantification of sleepiness: a new approach. Psychophysiology 1973; 10: 431-436.

16. Johns MW. A new method for measuring daytime sleepiness: the Epworth Sleepiness Scale. Sleep 1991; 14: $540-545$.

17. van Knippenberg FC, Passchier J, Heysteck D, et al. The Rotterdam Daytime Sleepiness Scale: a new daytime sleepiness scale. Psychol Rep 1995; 76: 83-87.

18. Guyatt GH, Bombardier C, Tugwell PX. Measuring disease-specific quality of life in clinical trials. Can Med Ass J 1986; 134: 889-895.

19. Juniper EF, Guyatt GH, Streiner DL. Clinical impact versus factor analysis for quality of life questionnaire construction. J Clin Epidemiol 1997; 50: 233-238. 
20. Shipper H, Clinch J, Powell V. Definition and conceptual issues. In: Spilker B, ed. Quality of life assessment in clinical trials. New York, Raven Press Ltd, 1990; pp. 11-24.

21. Strollo PJ, Rogers RM. Obstructive sleep apnea. N Engl J Med 1996; 334: 99-104.

22. Davis JA, Fine ED, Maniglia AJ. Uvulopalatopharyngoplasty for obstructive sleep apnea in adults: clinical correlation with polysomnographic results. Ear Nose Throat J 1993; 72: 63-66.

23. Gall R, Isaac L, Kryger M. Quality of life in mild obstructive sleep apnea. Sleep 1995; 16: S59-S61.

24. D'Ambrosio C, Bowman T, Mohsenin V. Quality of life in patients with obstructive sleep apnea: effect of nasal continuous positive airway pressure - a prospective study. Chest 1999; 115: 123-129.

25. Engleman HM, Kingshott RN, Wraith PK, Mackay
TW, Deary IJ, Douglas NJ. Randomized placebocontrolled crossover trial of continuous airway pressure for mild sleep apnea/hypopnea syndrome. Am J Respir Crit Care Med 1999; 159: 461-467.

26. Ware JE Jr, Sherbourne CD. The MOS 36-item short form health survey (SF-36): I. Conceptual framework and item selection. Med Care 1992; 30: 473-483.

27. Guyatt GH, Feeny DH, Patrick DL. Measuring health-related quality of life. Ann Intern Med 1993; 118: 622-629.

28. American Thoracic Society. Statement on health outcomes research in sleep apnea. Am J Respir Crit Care Med 1998; 157: 335-341.

29. Flemons WW, Reimer MA. Development of a diseasespecific health-related quality of life questionnaire for sleep apnea. Am J Respir Crit Care Med 1998; 158: 494-503. 